\title{
Patient and Spouse Perceived Quality of Life Five Years After Coronary Artery Bypass Graft Surgery
}

\author{
G.A. Lee* \\ Preventative Cardiology, Baker IDI Heart \& Diabetes Institute, Melbourne, Australia
}

\begin{abstract}
Health-related quality of life (HRQoL) was examined in patients' and their respective spouses' perspectives five years after cardiac bypass surgery. Participants completed the Short-Form 36 (SF-36) which consists of eight domains and two component summary scores measuring physical and mental HRQoL (PCS and MCS respectively). Paired $t$ tests were used to compare couples responses ( $\mathrm{n}=56$ pairs) with spouses recording higher (i.e. better scores) in the physicalrelated domains although differences were not significant. Statistically significant results were found between patients and spouses in emotional role, mental health, social functioning, energy/vitality and general health perceptions $(\mathrm{p}<0.001)$. The PCS were very similar for both the patient and spouses sample (45.9 v. 45.8 respectively, $\mathrm{p}=.829)$ and the MCS was significantly higher in the patients compared to the spouses $(54.8 \mathrm{v} .47 .7, \mathrm{p}<.001)$. The results demonstrated that spouses could accurately report the physical aspects of HRQoL but not the mental health of their partner.
\end{abstract}

\section{INTRODUCTION}

Coronary heart disease (CHD) is a common presentation with accompanying angina, breathlessness and fatigue. Coronary artery bypass grafting surgery (CABGS) is performed to alleviate these symptoms, prevent myocardial infarction (MI) and lead to better functional capacity and ultimately to improve quality of life (QoL). In 2005, 461,000 CABGS were performed in the United States [1] and 29,000 CABGS were performed in 2003 in the United Kingdom [2].

\section{HEALTH-RELATED QUALITY OF LIFE}

The primary objective of most clinical interventions such as CABGS, is to improve patients' health-related quality of life (HRQoL) and to establish if a particular treatment is beneficial [3]. Initially cardiac surgery research predominantly examined clinical outcomes such as mortality and morbidity. However, examining functional status and HRQoL along with biomedical data is now commonplace in CABGS patients. One of the problems is the lack of a consensus of a definition for HRQoL in relation to cardiac procedures $[4,5]$ although specific concepts have been identified as relevant to those with CHD. Wenger et al. maintained that three major factors reflect HRQoL: functional capacity (including physical, intellectual, social and emotional functioning), perceptions (levels of well-being and satisfaction with life) and effects of the symptoms of disease [6]. One paper has demonstrated that poor HRQoL after cardiac surgery identified patients at risk of reduced long-term survival [7], highlighting the importance of assessing HRQoL in CABGS patients.

A significant number of studies post CABGS have examined HRQoL in the immediate post-operative period [8-11]. These studies describe problems with physical functioning

*Address correspondence to this author at the Baker IDI Heart \& Diabetes Institute, Commercial Road, Prahran 3004, Melbourne, Australia;

E-mail: geraldine.lee@bakeridi.edu.au due to pain and issues associated with recovery such as comfort and discomfort, being sick and getting better [11] and perceiving the operation as an "enormity of the experience" and a major life event [11]. Other issues raised related to change in life view after CABGS with themes including acceptance and apprehension [10]. Other complications reported post CABGS include cognitive impairment and psychological issues such as the presence of anxiety and depression [12-15].

Longitudinal studies five to seven years after CABGS have shown relatively good HRQoL [16-19]. These studies have demonstrated a negative correlation between functional capacity and symptoms (i.e. those with symptoms such as angina have a corresponding decline in physical functioning). In a qualitative study of 62 patients seven years post CABGS, the main themes identified included physical wellbeing, emotional and cognitive well-being, lifestyle change and medication regimen [20]. The researchers also reported that the rehabilitation and recovery period was longer and more challenging than patients had anticipated. These studies highlighted that we should be concerned about the longer term HRQoL in those who have undergone CABGS, not just in the immediate post-operative period.

Evidence supporting the value of examining selfperceptions of health has previously been reported [21-23]. A person's perceived health status was associated with selfreported diseases in one study and in those who perceived themselves to be in poor health, concomitant illness was also noted [21]. The researchers concluded that self-reported health was a good proxy measure of self reported diseases. A correlation between poor self-rated health and short-term mortality post CABGS surgery was reported by Rumsfeld $e t$ al. [23] and others found poor self-rated health also predicted long term mortality especially in those with cardiovascular disease risk factors [22]. Although CABGS is an intervention, it must be borne in mind that $\mathrm{CHD}$ is a progressive condition and if risk factors such as hypertension and hypercholestraemia are untreated or sub-optimally treated post 
CABGS, further health problems will potentially ensue over time. Another factor known to affect health is increasing age. Although age can affect both physical and mental functioning, research shows that it was not necessarily a negative effect [24-26]. Older people appeared to report better HRQoL than younger individuals and one study demonstrated that older people were quite satisfied with their health despite their age and physical problems that could be clinically perceived as limiting or restricting health [26]. There is no doubt that self-reports are useful, in particular in those with CHD and CABGS.

\section{THE USE OF PROXY RESPONSES}

As well as self-reports on health, another method of evaluating HRQoL is to use proxy measures (that is a nominated person who can complete questionnaires on behalf of an individual- usually a close relative such as a spouse). The majority of studies related to the spouse's, specifically the wife's, role in care-giving with those suffering dementia and Alzheimer's disease with fewer studies in those with chronic diseases [27]. There was little research identified on the differences between spouses' perceptions of their partners' health and their partners' perceptions of their own health status. Yip et al. [28] highlighted the differences in responses between subjects and by their proxy (normally the spouse or a close relative). Moderate intra-class correlations were recorded with some domains showing better agreement than others. They recommended caution in using proxy responses in research on older adults based on their findings. However their research was carried out in residential facilities and so these results are probably not applicable to other cohorts. Other proxy studies have reported a systematic under-estimation of individuals' physical health in critical care areas but this was not surprising given the acute and serious nature of their relative's illness or a lack of understanding of the severity of the presenting problem $[29,30]$.

Specifically relating to CHD; several studies have sought information from spouses [31-35]. The majority of these studies were post MI and in the immediate post-operative period after cardiac surgery and highlighted the spousal distress associated with the cardiac event. The caregiver burden is also a major concern to spouses post CABGS [34]. Many studies report a change in spouses' role after interventions as they began to monitor and treat their partners' symptoms $[31,32]$. Spouses were more conservative in their estimation of the patients' physical capabilities and this was evident in several studies with some specifically related to cardiac rehabilitation [33]. Elliott et al. [35] examined HRQoL in 69 patients and their spouses pre-operatively, at hospital discharge and six months after CABGS using the SF-36 and the $15 \mathrm{D}$ (a health status questionnaire). They reported moderate to good agreement in physical functioning but only some psychosocial aspects. No studies were identified in the literature examining patient and spouses perceptions five years after CABGS.

\section{METHODOLOGY}

\section{Design \& Participants}

The purpose of the study was to assess patients' and their respective partners' perspectives of HRQoL five years after CABGS. Several assessments were made: subjective as- sessments by patients and their spouses of their views of the patients' HRQoL in terms of their physical functional health. Patients' psychological well-being, dietary habits, physical activity and cognitive performance were also assessed.

\section{Health Status Measurement}

The SF-36 was deemed a suitable HRQoL questionnaire. It can be self-administered or carried out by a researcher and has good psychometric qualities [36]. The questionnaire examined HRQoL on physical health (physical functioning, physical role limitations, bodily pain, energy and general health perceptions) and emotional health (mental health, social functioning and emotional role limitations). The role limitations allowed physical health problems and mental health problems to be included in evaluating HRQoL. The summary score measures were generated with the aim of reducing the number of statistical comparisons without the loss of information whilst reflecting both physical and mental health [37]. In the study, both the patient and the spouse used the adapted UK standard SF-36 Version 2. A detailed methodology has previously been published [16].

\section{Angina and Breathless Symptoms}

Angina and breathless symptoms were clinically assessed using the Canadian Cardiovascular Society score [38] and the New York Heart Association Classification [39] respectively.

\section{Procedures}

One hundred and sixty-two patients were initially recruited for a neuroprotective study and follow-up was carried out five years after their operation. All patients and their spouses were invited to attend and participate at the same time. The patients were invited to return 4.5 to 5.5 years after bypass surgery to the Middlesex Hospital in London for one visit answering questions about their perceptions on HRQoL. Their spouses were also invited to attend and give their view on the patient's health. Both parties were interviewed and completed questionnaires separately with no communication between patient and spouse until all questionnaires by both parties were complete.

All respondents were given reassurance regarding confidentiality. No clinical testing was carried out to confirm or deny their reported functional capacity (i.e. breathlessness or angina). The interviewer clarified problems with the questions (if there were any) but did not aid the respondents in their choice of answer. Ethical approval was given by the hospital ethics committee for the follow-up study.

\section{Statistical Analysis and Data Analysis}

SPSS $10.0{ }^{\circledR}$ was the statistical package used for data entry and analysis within the managed PC system. Continuous data was analysed using t tests. Analysis was via paired $t$ tests as both the spouse and the patient were reporting on the patient's HRQoL. The results using the SF- 36 questionnaire are presented with mean scores and standard deviations, in each of the eight domains and the Physical Component Summary (PCS) and the Mental Component Summary (MCS). The scores are normative based scores which gave a mean of 50 and standard deviation of 10, this allowed easier interpretation of results than comparing them to age-related population sample scores. 


\section{RESULTS}

From the original cohort, information was obtained on 156 patients (a trace rate of 96.3\%). One hundred and twenty-eight were followed up (which accounted for $79 \%$ of the sample). Fifty-six patients and their respective spouses completed the SF-36 questionnaire. The pre-operative, perioperative and interim characteristics of the patients are presented in Table 1. The mean age of the patients at the time of follow-up was 65.5 years (SD 7.5 years).

Table 1. Pre-Operative, Peri-Operative and Interim Characteristics of Patients $(n=56)$

\begin{tabular}{|c|c|}
\hline Characteristic & Number $(\%)$ \\
\hline \multicolumn{2}{|l|}{ Gender } \\
\hline Male & $49(87.5 \%)$ \\
\hline Female & $7(12.5 \%)$ \\
\hline Total & $56(100 \%)$ \\
\hline \multicolumn{2}{|c|}{ Pre-Operative Myocardial Infarction } \\
\hline Yes & $26(46.4 \%)$ \\
\hline No & $30(53.6 \%)$ \\
\hline \multicolumn{2}{|l|}{ Pre-Operative Angina (CCS) } \\
\hline CCS Class I & $0(0 \%)$ \\
\hline CCS Class II & $5(8.9 \%)$ \\
\hline CCS Class III & $47(83.9 \%)$ \\
\hline CCS Class IV & $4(7.1 \%)$ \\
\hline \multicolumn{2}{|c|}{ Pre-Operative Breathlessness (NYHA) } \\
\hline CCS Class I & $0(0 \%)$ \\
\hline CCS Class II & $25(44.6 \%)$ \\
\hline CCS Class III & $27(48.2 \%)$ \\
\hline CCS Class IV & $4(7.1 \%)$ \\
\hline \multicolumn{2}{|l|}{ No. of Vessels Grafted } \\
\hline One & $1(1.8 \%)$ \\
\hline Two & $15(26.8 \%)$ \\
\hline Three & $39(69.6 \%)$ \\
\hline Four & $1(1.8 \%)$ \\
\hline \multicolumn{2}{|l|}{ Interim Myocardial Infarction } \\
\hline Yes & $3(5.4 \%)$ \\
\hline No & $51(91.1 \%)$ \\
\hline Data missing & $2(3.6 \%)$ \\
\hline \multicolumn{2}{|c|}{ Five Years Post CABGS Angina (CCS) } \\
\hline CCS Class I & $38(67.9 \%)$ \\
\hline CCS Class II & $13(23.2 \%)$ \\
\hline CCS Class III & $5(8.9 \%)$ \\
\hline CCS Class IV & $0(0 \%)$ \\
\hline \multicolumn{2}{|c|}{ Five Years Post CABGS Breathlessness (NYHA) } \\
\hline CCS Class I & $34(60.7 \%)$ \\
\hline CCS Class II & $15(26.8 \%)$ \\
\hline CCS Class III & $7(12.5 \%)$ \\
\hline CCS Class IV & $0(0 \%)$ \\
\hline
\end{tabular}

The majority of patients were male (88\%) with less than half having a pre-operative MI. Pre-operatively the majority of patients had angina class III (84\%) and breathless symptoms Class II and III (93\%). From the time of CABGS to the time of follow-up (i.e. interim data), a total of three patients had a MI. Overall, patients' angina and breathless symptoms as measured by CCS and NYHA respectively, were minimal five years post CABGS compared to pre-operatively.

Examining the patient results in the first instance in Table 2, the mean score of four domains of emotional role, mental health, energy and general health perceptions were reported at or above 50. The remaining domains of physical functioning, physical role, social functioning and bodily pain were below 50 .

The PCS was 45.9 (which is below the normative population mean) while the MCS was 54.8, reflecting a well perceived overall mental health.

Table 2. Patients and Spouses' Mean Scores of SF-36 Results $(n=56)$

\begin{tabular}{|l|c|c|c|}
\hline \multicolumn{1}{|c|}{ Variable } & $\begin{array}{c}\text { Patient } \\
\text { Sample (SD) }\end{array}$ & $\begin{array}{c}\text { Spouse } \\
\text { Sample (SD) }\end{array}$ & $\begin{array}{c}\text { p Value } \\
(\mathbf{2} \text { Tail sig.) }\end{array}$ \\
\hline \hline Physical functioning & $45.2(12.7)$ & $47.1(11.7)$ & .068 \\
\hline Physical role & $49.8(9.9)$ & $51.7(8.3)$ & .180 \\
\hline Emotional role & $51.8(9.2)$ & $50.3(11.0)$ & .252 \\
\hline Mental health & $55.2(9.5)$ & $46.5(5.6)$ & $<.001$ \\
\hline Social functioning & $46.1(8.6)$ & $35.8(4.1)$ & $<.001$ \\
\hline Energy Vitality & $52.5(9.5)$ & $44.9(5.5)$ & $<.001$ \\
\hline Bodily pain & $47.3(10.1)$ & $48.2(9.9)$ & .488 \\
\hline $\begin{array}{l}\text { General health } \\
\text { perceptions }\end{array}$ & $50.4(10.7)$ & $36.9(5.4)$ & $<.001$ \\
\hline $\begin{array}{l}\text { Physical Component } \\
\text { Summary }\end{array}$ & $45.9(11.0)$ & $45.8(7.1)$ & 1.00 \\
\hline $\begin{array}{l}\text { Mental Component } \\
\text { Summary }\end{array}$ & $54.8(7.7)$ & $47.7(6.4)$ & $<.001$ \\
\hline
\end{tabular}

Examining the spouses' results on the patients' HRQoL demonstrated that six of the domain scores of physical functioning, mental health, vitality, social functioning and general health perceptions as well as the component summary scores were below 50 . With two domains for social functioning and general health perceptions were less than 40 (i.e. greater than 1 standard deviation below the norm). Only physical role and emotional role were at 50 or above.

Comparing the patient and the spouse domain scores revealed significant differences in four of the eight domains: mental health, social functioning, energy and general health perceptions $(p<.001)$ with the spouse scoring much lower than the patient (i.e. reflecting poorer HRQoL). Spouses scores on three domains (physical functioning, bodily pain and physical role) were higher (i.e. better) than the patients but did not reach statistical significance. The PCS results were remarkably similar for both patient sample and their spouses (45.9 v. 45.8 respectively). However there was a higher mean in the MCS from the patient sample (54.8) compared to their spouses' replies $(47.7)(\mathrm{p}<.001)$. Thus, the component summaries demonstrated a significant difference in mental health but not in physical health. 


\section{DISSCUSION}

In this study using the SF-36, a relatively good HRQoL was evident five years post CABGS. Overall patient reported HRQoL was good five years post CABGS and compared to their spouses responses; similarities were seen in the physical health related domains of physical functioning, physical role, bodily pain and PCS. However, significant differences between the patient and their spouse were evident in the mental health, social functioning, vitality and general health perceptions domains and more importantly the mental component summary. The study demonstrated that self-reports from patient and spouse reports are valid in measuring physical HRQoL.

Previous studies have highlighted the longitudinal benefits of CABGS in terms of HRQoL using a variety of tools [1720]. With respect to symptoms, the majority of patients in this study had minimal angina and breathless symptoms at followup and this has previously been correlated to good functional capacity $[17,18,21]$. The lack of symptoms confirms the SF36 results observed (i.e. the majority of patients have good functional capacity). Other determinants that affected HRQoL were examined (including anxiety and depression and the presence of other illnesses) and these were presented in another paper [40].

It seemed that a spouse could precisely score physical health relating to activities of daily living but contradictory data emerged from the psychological interpretation of another's health, a view confirmed by Yip et al. [28]. Given the high level of agreement between patient and spouse responses in physical health, it seems that the proxy response is valid and reliable. This finding is in keeping with previous studies $[28,35]$. Although other studies have reported underestimation of physical health by proxies; these were in critically ill patients [29, 30]. Clearly there was some discrepancy about whether the responses between a respondent and their proxy were valid and reliable. Hartman Ellis et al. [41] calculated the propensity score (the probability that an individual belonged to a proxy respondent group) and reported that the differences between respondent and proxy responses were substantially reduced in some measures but the differences in the SF-36 were still evident. This finding justifies use of the SF-36 in this study.

The reasons for the differences between the patient and spouse responses with the MCS may be simply that it was difficult for spouses to assess patients' feelings and mental well-being. From previous studies, mental health was identified as more difficult to perceive and report than physical health as the patient may not express his or her feelings [35]. In addition, studies of mental health stated that male patients reported higher scores than their female counterparts, with women reporting poorer health [42]. The other explanation for the findings was that women as spouses were more conservative in their answers than the male counterparts (hence the lower scores). However, this study was not seeking to identify differences between genders in proxy responses so no conclusions can be drawn.

Other studies have advocated examining the spouses own HRQoL as proxies own psychological distress which will influence their answers on their spouse's health [27]. However, it could be argued that their results would still be relevant and are probably still valid. The issue of caregiver burden has previously been reported and is probably valid in the early postoperative recovery period [34]. Spousal distress would potentially affect their own health as well as that of their partner. The longer term issue of spousal distress post CABGS has not been investigated but probably requires further exploration.

The proxy response can be used to compare with the patients' responses but it may also be beneficial in cases where patients post CABGS are unable to complete HRQoL questionnaires such as those with anxiety or depression or neuropsychological deficits after surgery [12-14].

The SF-36 was chosen because of its wide use in cardiac studies and its ability to examine functional ability in cardiac patients [24]. Examining patient perceived HRQoL can reveal problems of physical and emotional health and completing HRQoL questionnaires is not time consuming or expensive and can allow further regular or intermittent clinical assessment if health problems are detected. Given that atherosclerosis is a progressive condition and thus a chronic condition, it is important to examine HRQoL longitudinally (especially after interventions such as CABGS). This body of knowledge can reveal problems in physical and emotional health. Patients may require further interventions to manage conditions (such as chronic hypercholestramia, hypertension and diabetes).

However an important fact was that patients generally regard themselves as healthy five years post CABGS. One question is whether patients have changed their perceptions and beliefs since their operation. Psychological adaptation is one plausible explanation for their perceived HRQoL. Change in perceptions over time were not examined within this study but is an issue which warrants further investigation.

One of the limitations is that a lack of baseline data can lead to difficulty in predicting outcome. It seems reasonable to gain accurate information on the benefits of surgery to carry out a prospective study from the pre-operative time-point. One limitation of the study is that HRQoL pre-operatively was not examined and therefore, it is difficult to draw conclusions post CABGS with no baseline available. As in line with previous studies, the majority of patients were male $[8,11,35]$.

\section{CONCLUSIONS}

Spouses can accurately report physical HRQoL but differences emerge when reporting on the emotional aspects. These findings can provide the impetus for further work in this area. Examining quality of life from the patient's perspective and that of their spouse allows health professionals to combine their clinical objective findings and the personal subjective experience and hopefully improve patient care in those undergoing CABGS. The completion of HRQoL questionnaires is not time consuming or expensive and questionnaires can be administered and allow further regular or intermittent clinical assessment if health problems are detected. Patients may require further interventions to manage conditions and this study demonstrates that the spouse's opinions are valid in assessment HRQoL five years after CABGS.

\section{REFERENCES}

[1] Rosamond W, Flegal K, Furie K, et al. American Heart Association. Heart Disease and Stroke Statistics - 2008 Update. Dallas, Texas: American Heart Association 2008; 117(4): 25-146. 
[2] Allender S, Peto V, Scarborough P, Boxer A, Rayner M. Coronary heart disease statistics. London: British Heart Foundation; 2007.

[3] Stewart AL, Ware SJ, Sherbourne, Wells KB. Psychological distress, well-being and cognitive functioning measures. In Stewart AL, Ware JE, Eds. Measuring functioning and well-being: The medical outcomes study approach. Durham, North Carolina: Duke University Press; 1992.

[4] Smith KW, Avis NE, Assmann SF. Distinguishing between quality of life and health status in quality of life research: A meta-analysis. Qual Life Res 1999; 8: 447-59.

[5] Bowling A. Measuring Disease: A review of disease-specific quality of life measurement scales. Buckingham: Open University Press; 1995.

[6] Wenger NK, Mattson ME, Furberg CD, Elinson J, Eds. Assessment of quality of life in Clinical Trials of Cardiovascular Therapies. New York: LeJacq Publishing; 1984.

[7] Koch CG, Li L, Sabik J, Starr NJ, Blackstone EH. Effect of functional health-related quality of life on long-term survival after cardiac surgery. Circulation 2007; 115: 692-9.

[8] Ballan A, Lee G. Patient perceived quality of life pre and post coronary artery bypass graft surgery. Aust J Adv Nurs 2007; 24 (4): 24-8.

[9] Huber CH, Goeber V, Berdat P, Carrel T, Eckstein F. Benefits of cardiac surgery in octogenarians - A postoperative quality of life assessment. Eur J Cardiothorac Surg 2007; 31: 1099-105.

[10] Gardner G, Elliott D, Gill J, Griffin M, Crawford M. Patient experiences following cardiothoracic surgery: An interview study. Eur J Cardiovasc Nurs 2005; 4(3): 242-50.

[11] Lindsay GM, Smith LN, Hanlon P, Wheatley DJ. Coronary artery disease patients' perception of their health and expectations of benefit following coronary artery bypass grafting. J Adv Nurs 2000; 32 (6): 1412-21.

[12] Goyal TM, Idler EL, Krause TJ, Contrada RJ. Quality of life following cardiac surgery: Impact of the severity and course of depressive symptoms. Psychosom Med 2005; 67 (5): 759-65.

[13] Rothenhausler HB, Grieser B, Nollert G, Reichart B, Schelling G, Kapfhammer HP. Psychiatric and psychosocial outcome of cardiac surgery with cardiopulmonary bypass: A prospective 12-month follow-up study. Gen Hosp Psychiatry 2005; 27 (1): 18-28.

[14] Rymaszewska J, Kiejna A, Hadrys T. Depression and anxiety in coronary artery bypass grafting patient. Eur Psychiatry 2003; 18 (4): 155-60.

[15] Selnes OA, Royall RM, Grega MA, Borowicz LM, Quakey S, McKhann GM. Cognitive changes 5 years after coronary artery bypass grafting. Arch Neurol 2001; 58: 598-604.

[16] Lee G. Patients reported health related quality of life five years post Coronary Artery Bypass Graft Surgery- a methodological study. Eur J Cardiovasc Nurs 2008; 7 (1): 67-72.

[17] Herlitz J, Wiklund I, Sjoland $\mathrm{H}$ et al. Impact of age on improvement in health-related quality of life five years after coronary artery bypass grafting. Scand J Rehab Med 2000; 32: 41-8

[18] Caine N, Sharples LD, Wallwork J. Prospective study of quality of life before and after coronary artery bypass grafting: outcome at five years. Heart 1999; 81: 347-51.

[19] Herlitz J, Wiklund I, Caidahl K et al. Determinants of an impaired quality of life five years after coronary artery bypass surgery. Heart 1999; 81: 342-6.

[20] Tolmie EP, Lindsay GM, Belcher PR. Coronary artery bypass graft operation:Patients' experience of health and well-being over time. Eur J Cardiovasc Nurs 2006; 5:228-36.

[21] Goldberg P, Gueguen A, Schmaus A, Nakache JP, Goldberg M. Longitudinal study of associations between perceived health status and self reported diseases in the French Gazel cohort. J Epidemiol Comm Health 2001; 55: 233-8.

[22] Heistaro S, Jousilhati P, Lahelma E, Vartianen E, Puska P. Self rated health and mortality: a long term prospective study in eastern Finland. J Epidemiol Comm Health 2001;55 (4): 227-32.
[23] Rumsfeld JS, Mawhinney S, McCarthy M et al. Health-related quality of life as a predictor of mortality following coronary artery bypass graft surgery. Participants of the department of Veterans Affairs Cooperative Study Group in processes, structures and outcomes of care in cardiac surgery. JAMA 1999; 281 (14): 1298-303.

[24] Fruitman DS, MacDougall CE, Ross DB. Cardiac surgery in octogenarians: can elderly patients benefit? Quality of life after cardiac surgery. Ann Thorac Surg 1999; 68 (6): 2129-35.

[25] Singer MA, Hopman WM, MacKenzie TA. Physical functioning and mental health in patients with chronic conditions. Qual Life Res 1999; 8 (8): 687-91.

[26] Pit SW, Nair BR, Byles J, Heller RF. Use of the Short-Form-36 health survey to assess quality of life among Australian elderly. Australian J Ageing 1996; 15 (3): 132-5.

[27] Hagedoorn M, Sanderman R, Ranchor AV, Brilman EI, Kempen GI, Ormel J. Chronic disease in elderly couples: are women more responsive to their spouses' health condition than men? J Psychosom Res 2001; 51(5): 693-6.

[28] Yip JY, Wilber KH, Myrtle RC, Grazman DN. Comparison of older adult subject and proxy responses on the SF-36 health-related quality of life instrument. Age Ment Health 2001; 5 (2): 136-42.

[29] Hofhuis J, Hautvast JL, Schrijvers AJ, Bakker J. Quality of life on admission to the intensive care: can we query the relatives? Intens Care Med 2003; 29 (6): 974-9.

[30] Weinfurt KP, Trucco SM, Willke RJ, Schulman KA. Measuring agreement between patient and proxy responses to multidimensional health-related quality-of-life measures in clinical trials: An application of psychometric profile analysis. J Clin Epidem 2002; 55: 60818.

[31] Moser D, Dracup K. Role of spousal anxiety and depression in patients' psychosocial recovery after a cardiac event. Psychosom Med 2004; 66(4): 527-32.

[32] Lukkarinen $\mathrm{H}$, Kyngas $\mathrm{H}$. Experiences of the onset of coronary artery disease in a spouse. Eur J Cardiovasc Nurs 2003; 2(3): 189-94.

[33] Phillips WT, Alexander JL, Pepin V, Riley C. Cardiac rehabilitation patient versus proxy quality-of-life perceptions. Clin Nurse Res 2003; 12(3): 282-93.

[34] Halm MA, Treat-Jacobson D, Lindquist R, Savik K. Caregiver burden and outcomes of caregiving of spouses of patients who undergo coronary artery bypass graft surgery. J Acute Crit Care 2007; 36 (3): 170-87.

[35] Elliott D, Lazarus R, Leeder SR. Proxy respondents reliably assessed the quality of life of elective cardiac surgery patients. J Clin Epidemiol 2006; 59: 153-9.

[36] Ware JE, Snow KK, Kosinski M. The SF-36 Health Survey: Manual and interpretation guide. Boston: Health Institute; New England Medical Centre: 1988.

[37] Jenkinson C, Layte R, Lawrence K. Development and testing of the medical outcomes study 36 -item short form health survey summary scale scores in the United Kingdom. Med Care 1997; 35 (4): 410-6.

[38] Campeau L. Grading of angina pectoris. Circulation 1976; 54: 522- 3

[39] The Criteria Committee of the New York Heart Association. Diseases of the Heart and Blood Vessels: Nomenclature and Criteria for Diagnosis. 6th ed. Boston, Mass: Little Brown: 1974.

[40] Lee G. Determinants of quality of life five years after Coronary Artery Bypass Graft Surgery. Heart Lung J 2008. In press.

[41] Hartman EB, Bannister WA, Cox JK et al. Utilization of the propensity score method: an exploratory comparison of proxy-completed to self-completed responses in the Medicare Health Outcomes Survey. Health and Quality of Life Outcomes 2003; 1:47.

[42] Jenkinson C, Coulter A, Wright L. Short form 36 (SF-36) Health Survey Questionnaire: Normative data for adults of working age. BMJ 1993; 306: 1437-40. 